- The belief that HCQ is "Very important" (12.9\% "low") rather than "important" (22.1\% "low") or "not important / useless" (33.1\% "low").

- Taking many different medications (9.8\% "low" for Patients indicating more than 7 medications vs $19.8 \%$ for those listing 3 or less)

Childhood onset of the SLE was associated with a lower adherence (30.0\% "low" vs. $17.4 \%$ for later onset SLE $(p<.001)$

658 patients $(29.6 \%)$ reported having experienced side effects. $42.6 \%$ of them stopped taking HCQ (patient led 161, doctor led 110, unclear 9). Amongst those continuing HCQ despite experiencing side effects, the proportion of non adherent patients increased to $24.7 \%$, compared to $15.2 \%$ in the group of patients that have not experienced side effects $(p=.0001)$. The 232 patients who talked with their Doctor and felt listened to appear to adhere better (22.0\% low adherence) than the 84 who did not feel heard $(31.0 \%$ low adherence), but the significance is only directional $(p=<0.15)$

523 patients have used HCQ in the past. 206 (39.4\%) consider the decision to stop HCQ as doctor initiated, $272(52.0 \%)$ as patient initiated, and $36(6.9 \%)$ as a joint decision.

When stopping was patient initiated, $59.9 \%$ was due to experiencing a significant side effect attributed by the patient to $\mathrm{HCQ}, 6.7 \%$ due to concern of a potential side effect, $11.2 \%$ "tested" stopping and noticed no difference, $10.0 \%$ were not convinced that it worked, $8.2 \%$ felt their lupus was less active, $2.6 \%$ wanted to reduce pill consumption. (Side effects attributed to HCQ may relate to age, disease activity or other factors).

Conclusion: Doctors can help HCQ adherence by boosting patient's confidence in the importance of $\mathrm{HCQ}$. Better patient education may contribute to avoid up to $40 \%$ of patient initiated decision to stop HCQ treatment.

References:

[1] Fanouriakis A et al. 2019 update of the EULAR recommendations for the management of systemic lupus erythematosus. Ann Rheum Dis. 2019 Jun; 78(6): 736-745

[2] Costedoat $\mathrm{N}$ et al, Treatment adherence in systemic lupus erythematosus and rheumatoid arthritis: time to focus on this important issue, Rheumatology, Vol 57 (9), Sep 2018, 1507-1509.

Disclosure of Interests: None declared

DOI: 10.1136/annrheumdis-2020-eular.3233

\section{AB0372 $\quad$ PREGNANCY OUTCOME IN WOMEN WITH SJÖGREN SYNDROME IS OFTEN COMPLICATED BY PLACENTA INSUFFICIENCY}

I. Troester ${ }^{1}$, F. Kollert ${ }^{2}$, A. Zbinden ${ }^{2}$, L. Raio ${ }^{3}$, F. Foerger ${ }^{2}{ }^{1}$ University Hospital and University of Bern, Inselspital, Pediatrics, Bern, Switzerland; ${ }^{2}$ University Hospital and University of Bern, Inselspital, Rheumatology, Immunology and Allergology, Bern, Switzerland; ${ }^{3}$ University Hospital and University of Bern, Inselspital, Obstetrics, Bern, Switzerland

Background: Chronic inflammatory rheumatic diseases are often associated with a negative effect on pregnancy outcome. Most obstetrical complications are placenta-mediated such as preterm delivery and growths restrictions. In women with Sjögren syndrome, data on placenta- mediated complications are scarce and conflicting $(1,2)$.

Objectives: To analyse neonatal outcome in women with Sjögren syndrome with focus on preterm delivery and growth restriction.

Methods: We retrospectively analysed 23 pregnancies of 16 patients with Sjögren syndrome that were followed at our centre with regard to pregnancy outcome, medication and disease characteristics. Small for gestational age was defined as birthweight percentile $<10^{\text {th }}$. Preterm delivery was defined as delivery before 37 , early term as delivery between 37-39 and term as delivery between 39-42 weeks of gestation.

Results: Of 23 pregnancies, one ended in a miscarriage and 22 resulted in live births including one set of twins. Treatment used during pregnancy was hydroxychloroquine (20 pregnancies), prednisone (8), azathioprine (5) and cyclosporine (2). Concomitant treatment with low-dose aspirin was used in 9 pregnancies.

Of the 22 live births, 17 were born at early term and 5 at term. There were no preterm deliveries. Median birth weight was $2820 \mathrm{~g}$ (range 2095-3845g). Nine newborns (40.9\%) were small for gestational age (SGA). Maternal treatment during these pregnancies was hydroxychloroquine in all cases and additional lowdose aspirin in three cases. Elevated CRP levels during pregnancy were found in $57 \%$ of the cases with SGA outcome. Only one woman with an SGA infant had positive anti-phospholipid antibodies.

Regarding delivery mode, most patients had caesarean sections.

Conclusion: In our cohort of women with Sjögren syndrome the prevalence of small for gestational age infants was high despite maternal treatment with hydroxychloroquine. Inflammatory markers could help to identify the patients at risk for placental insufficiency, yet prospective studies of larger cohorts are needed.

\section{References:}

[1] Gupta S et al; Sjögren Syndrome and Pregnancy: A literature review. Perm J 2017; 21:16-047

[2] De Carolis S et al; The impact of primary Sjögren's syndrome on pregnancy outcome: Our series and review of the literature. Autoimmun Rev 2014; 13(2):103-7

Disclosure of Interests: Isabella Troester: None declared, Florian Kollert Employee of: Novartis, Astrid Zbinden: None declared, Luigi Raio: None declared, Frauke Foerger Grant/research support from: unrestricted grant from UCB, Consultant of: UCB, GSK, Roche, Speakers bureau: UCB, GSK DOI: 10.1136/annrheumdis-2020-eular.5725

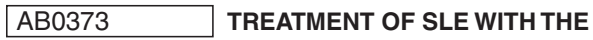 IMMUNOPROTEASOME INHIBITOR KZR-616: RESULTS FROM THE FIRST 4 COHORTS OF THE MISSION STUDY, AN OPEN-LABEL PHASE 1B DOSE ESCALATION TRIAL}

R. Furie $^{1}$, S. Parikh ${ }^{2}$, A. Maiquez ${ }^{3}$, A. Khan ${ }^{4}$, O. Moreno ${ }^{3}$, M. Soneira ${ }^{4}$, C. Kirk ${ }^{5}$, D. Bomba ${ }^{5}$, K. Harvey ${ }^{5}$, M. K. Farmer ${ }^{5} .{ }^{1}$ Northwell Health, Great Neck, NY, United States of America; ${ }^{2}$ The Ohio State University Wexner Medical Center, Columbus, United States of America; ${ }^{3}$ SouthCoast Research Center, Inc, Miami, United States of America; ${ }^{4}$ Accurate Clinical Research, Houston, United States of America; ${ }^{5}$ Kezar Life Sciences, South San Francisco, United States of America

Background: Non-specific proteasome inhibitors, such as bortezomib (BTZ), target the constitutive proteasome and immunoproteasome and are approved treatments for multiple myeloma ${ }^{1}$. BTZ has also been used to treat systemic lupus erythematosus (SLE) and lupus nephritis (LN); however, treatment emergent adverse events (TEAEs), such as gastrointestinal (GI) effects, hematologic abnormalities, asthenia and peripheral neuropathy, limi its use as a long-term treatment option for chronic autoimmune disease ${ }^{2}$ KZR-616 is a first-in-class selective immunoproteasome inhibitor and is highly active in murine $\mathrm{SLE}^{3}$. Subcutaneous (SC) administration of KZR-616 (30 and $45 \mathrm{mg}$ weekly [QW]) was demonstrated as safe and well-tolerated, and successfully achieved target levels of immunoproteasome inhibition in healthy volunteers ${ }^{4,5}$.

Objectives: We report the preliminary safety and efficacy of KZR-616 in the first 4 cohorts of the Phase 1b portion of Study KZR-616-002 in patients with active SLE (NCT03393013)

Methods: SLE patients (per SLICC Classification Criteria) with SLEDAI $\geq 4$ despite stable background immunosuppressant, anti-malarial, and/or corticosteroid ( $\leq 20 \mathrm{mg}$ prednisone equivalent) therapy in this open-label multicentric dose-escalation trial received KZR-616 at doses of $45 \mathrm{mg}$ (Cohort 1), 60mg (Cohort 2), or $30 \mathrm{mg}$ with escalation to $60 \mathrm{mg}$ (Cohorts $2 \mathrm{a}$ and $2 \mathrm{~b}$ ) SC weekly through Week 13 (W13) with 12 weeks of follow-up. Efficacy measures included SLEDAI, Cutaneous Lupus Erythematous Disease Area and Severity Index, 28 tender and swollen joint counts, Physicians Global Assessment, Patient Global Assessment, and Patient Assessment of Pain, in evaluable patients (those who received $\geq 1$ month of KZR-616).

Results: As of 16 January 2020, 33 patients had enrolled and received at least 1 dose of KZR-616. The majority of TEAEs have been mild or moderate with no reported peripheral neuropathy, prolonged GI-related AEs, and no clinically significant laboratory AEs. There were 3 treatment emergen SAEs, one each of thrombotic microangiopathy (Cohort 2), localized herpes zoster (Cohort 2a), and systemic inflammatory response syndrome (Cohort 2a) with the latter 2 patients completing the full 13 weeks of treatment after resolution. When compared to baseline, improvement in all measures of disease activity were seen at W13 and maintained or improved during the follow-up period, and $94 \%$ of evaluable patients had improvements on at least 2 measures/assessments of disease activity. A single patient with active class IV/V nephritis was enrolled on prednisone $10 \mathrm{mg}$, leflunomide $10 \mathrm{mg}$, and hydroxychloroquine $200 \mathrm{mg}$ /day; nephrotic-range proteinuria at baseline $(3.85 \mathrm{~g} /$ day) decreased to $0.6 \mathrm{~g} /$ day 4 weeks after the last dose of KZR-616.

Conclusion: Weekly subcutaneous administration of KZR-616 at 45 and $60 \mathrm{mg}$ was safe and well-tolerated. Evidence of disease suppression at W13 in active SLE patients on stable background therapy was observed. In addition, one study participant with active proliferative nephritis was enrolled with significant reduction in proteinuria. The Phase 2 portion of this study in active proliferative $L N$ is open for enrollment.

References:

[1] Scott K. et al. Cochrane Database Syst Rev 2016;4:CD010816 
[2] Alexander T et al. Ann Rheum Dis 2015;74: 1474-8

[3] Muchamuel T. et al. Ann Rheum Dis 2018;77: A685

[4] Lickliter J. et al. Ann Rheum Dis 2018;77: A1413

[5] Furie R et al. Ann Rheum Dis 2019;78: A776

Disclosure of Interests: Richard Furie Grant/research support from: AstraZeneca, Biogen, Consultant of: AstraZeneca, Biogen, SV Parikh Grant/research support from: Aurinia Pharmaceuticals, EMD-Serono, Consultant of: Aurinia, BMS, GSK, Adonis Maiquez: None declared, Amber Khan: None declared, Orlando Moreno: None declared, Miguel Soneira: None declared, Christopher Kirk Shareholder of: Kezar Life Sciences, LLC, Employee of: Kezar Life Sciences, LLC, Darrin Bomba Shareholder of: Kezar Life Sciences, LLC, Employee of: Kezar Life Sciences, LLC, Ken Harvey Shareholder of: Kezar Life Sciences, LLC, Employee of: Kezar Life Sciences, LLC, Mary Katherine Farmer Shareholder of: Kezar Life Sciences, Employee of: Kezar Life Sciences

DOI: 10.1136/annrheumdis-2020-eular.2700

\section{$\mathrm{AB} 0374$ \\ LUPUS LOW DISEASE ACTIVITY STATE AND MAINTAINING DRUG THERAPY: A RETROSPECTIVE INVESTIGATION}

E. Gotelli ${ }^{1}$, A. Sulli ${ }^{1}$, G. Ferrari ${ }^{1}$, G. Pacini ${ }^{1}$, C. Schenone ${ }^{1}$, M. Patanè ${ }^{1}$, P. F. Bica ${ }^{1}$, C. Pizzorni ${ }^{1}$, M. Cutolo ${ }^{1}$, S. Paolino ${ }^{1} .{ }^{1}$ Research Laboratory and Academic Division of Clinical Rheumatology, Department of Internal Medicine, IRCCS Polyclinic Hospital San Martino, University of Genoa, Genoa, Italy, Genova, Italy

Background: Systemic lupus erythematosus (SLE) is a chronic autoimmune multisystemic disease, that can begin with a wide range of clinical manifestations, and requires immunosuppressive therapies (1). A treat-to-target strategy leads to a high rate of clinical remission among patients (2). Several "remission" definitions have been provided in the last years and Lupus Low Disease Activity State (LLDAS) seems one of the best tools to evaluate it in clinical practice (3).

Objectives: To evaluate the prevalence of SLE signs and symptoms at onset and the drugs used to induce and maintain the clinical remission, evaluated by LLDAS, in a real-life cohort of SLE patients.

Methods: Thirty female SLE patients (mean age $52 \pm 15$ years; mean age at disease onset $34 \pm 16$ years, mean disease duration $18 \pm 13$ years) in clinical remission have been enrolled (EULAR/ACR 2019 criteria) (4). Remission was defined by LLDAS (SLEDAI-2K $<4$ and no activity in major organ systems, no hemolytic anemia; no new features of activity compared with previous assessment, physician global assessment $(P G A) \leq 1$, prednisone dose $\leq 7.5 \mathrm{mg} /$ day, well tolerated and stable therapy with maintenance doses of immunosuppressive drugs). Clinical and serological manifestations, SLE$\mathrm{DAI}-2 \mathrm{~K}$ and pharmacological treatments were recorded at baseline and during follow-up.

Results: Mucocutaneous involvement (57\%), arthritis (30\%), serositis (30\%), nephritis $(27 \%)$, leukopenia $(23 \%)$, thrombocytopenia $(20 \%)$, hemolytic anemia $(13 \%)$, antiphospholipid syndrome manifestations (16\%), neuro-psychiatric lupus symptoms $(6 \%)$ were present in various combinations at disease onset. Baseline mean SLEDAI-2K was $10.5 \pm 2.5$. Patients were treated with different dosages of glucocorticoids (100\%), hydroxychloroquine ( $\mathrm{HCQ}, 73 \%)$, cyclofosfamide (20\%), mycophenolate mofetile (MMF, 13\%), azathioprine (AZA, 13\%), methotrexate (MTX, 13\%), cyclosporine A (CSA, 6\%), rituximab $(3 \%)$, abatacept (ABA, 3\%). Glucocorticoids were prescribed together with a single DMARD in $50 \%$ of cases and with two DMARDs in the remaining $50 \%$ of patients. Patients reached LLDAS remission after a mean time of $14 \pm 12$ years, with a mean remission duration of $4.2 \pm 3.2$ years (mean SLEDAI-2K at last visit $1 \pm 1$; Mean $P G A \quad 0.4 \pm 0.1$ ). Maintenance therapies during remission were prednisone $\leq 5 \mathrm{mg} /$ day and/or $\mathrm{HCQ} \leq 400 \mathrm{mg} /$ day and/or CSA $\leq 200 \mathrm{mg} /$ day and/or MTX $\leq 10 \mathrm{mg} /$ weekly and/or MMF $\leq 2 \mathrm{~g} /$ day and/or AZA $\leq 100 \mathrm{mg} /$ day. In particular, only prednisone $7 \%$, only $\mathrm{HCQ} 3 \%$, prednisone + $\mathrm{HCQ} 53 \%$, prednisone + single DMARD (different from $\mathrm{HCQ}$ ) $7 \%$, prednisone + $\mathrm{HCQ}+$ DMARDs $30 \%$.

Conclusion: After reaching the clinical remission by a treat to target strategy, the administration of low dose of prednisone and $\mathrm{HCQ}$ in the majority of SLE patients $(63 \%)$ seems useful to prevent new SLE flares. The retrospective design and the absence of a control group of patients with active disease limit this study.

References:

[1] Lisnevskaia L et al. 2014. Lancet 384(9957):1878-1888.

[2] Van Vollenhoven RF et al. 2014. Ann Rheum Dis 73(6): 958-967.

[3] Franklyn K et al. 2016. Ann Rheum Dis. 75(9): 1615-21.

[4] Aringer M et al. 2019. Arthritis Rheumatol. 71(9): 1400-1412.

Disclosure of Interests: Emanuele Gotelli: None declared, Alberto Sulli Grant/ research support from: Laboratori Baldacci, Giorgia Ferrari: None declared, Greta Pacini: None declared, Carlotta Schenone: None declared, Massimo Patanè: None declared, Pietro Francesco Bica: None declared, Carmen Pizzorni: None declared, Maurizio Cutolo Grant/research support from: Bristol-Myers Squibb,

Actelion, Celgene, Consultant of: Bristol-Myers Squibb, Speakers bureau: Sigma-Alpha, Sabrina Paolino: None declared DOI: 10.1136/annrheumdis-2020-eular.5268

\begin{tabular}{|l}
\hline AB0375 \\
SAFETY AND BENEFICIAL EFFECTS OF \\
HYDROXYCHLOROQUINE ON PREGNANCY \\
OUTCOMES IN WOMEN WITH SYSTEMIC LUPUS \\
ERYTHEMATOSUS
\end{tabular}

I. Haase ${ }^{1}$, R. Brinks ${ }^{1}$, M. Schneider ${ }^{1}$, R. Fischer-Betz ${ }^{1}{ }^{1}$ Heinrich-HeineUniversity Düsseldorf, Policlinic of Rheumatology \& Hiller Research Unit, Düsseldorf, Germany

Background: The use of hydroxychloroquine (HCQ) has long been established in Systemic Lupus Erythematosus (SLE) and especially as applicable drug during pregnancy. Recently, beneficial effects and safety of $\mathrm{HCQ}$ have been re-discussed in the light of a change in the summary of product characteristics in some countries. More current studies are required to provide patients with evidence-based advice regarding this essential drug when counselling for pregnancy.

Objectives: To examine the impact of $\mathrm{HCQ}$ on pregnancy outcomes of SLE women.

Methods: Pregnancies of women with SLE from an outpatient pregnancy clinic were prospectively evaluated before and throughout gestation. Maternal and fetal outcomes in women without HCQ therapy (group A) were compared to pregnancies under $\mathrm{HCQ}$ treatment from $1^{\text {st }}$ trimester on (group $\mathrm{B}$ ). A multiple logistic regression was performed with adjustment for confounding factors.

Results: We enrolled 184 live births from singleton pregnancies in 145 women ( $n=77$ with $\mathrm{HCQ}$ and $n=107$ w/o HCQ). One neonatal death (group B) occurred after severe preeclampsia at 24 weeks of gestation $(w / g)$ linked to noncompliance in a woman with high-risk aPL profile. One child (group B) was born with mycophenolate mofetil embryopathy.

Women in the HCQ group had a significantly lower rate of preterm births [aOR 0.31 (95\%-Cl: 0.15-0.64), $\mathrm{p}=0.026$ ]. Regarding preeclampsia, we found a tendency towards less incidence with the use of $\mathrm{HCQ}$ [aOR $0.49(95 \%-\mathrm{Cl}$ : 0.231.03), $p=0.24$ ]. These improved outcomes are opposed by a higher frequency of risk factors in group B (lupus nephritis, high-risk aPL profile, slightly more hypertension) and a tendency towards more severe SLE (expressed in terms of increased use of Azathioprine) (Table 1). Nevertheless, women with HCQ

Table 1. Patient characteristics \& pregnancy outcomes

\begin{tabular}{|c|c|c|c|c|}
\hline & & $\begin{array}{l}\text { All pregnancies } \\
\qquad(n=184)\end{array}$ & $\begin{array}{c}\text { No } H C Q \text { in } \\
\text { pregnancy } \\
(n=107)\end{array}$ & $\begin{array}{l}\text { HCQ during } \\
\text { pregnancy } \\
(n=77)\end{array}$ \\
\hline & $\begin{array}{l}\text { Age (years), median } \\
\text { (IQR) }\end{array}$ & $31.0(28.0-34.0)$ & $31.0(29.0-34.0)$ & $30.0(27.0-33.0)$ \\
\hline & Hypertension, n (\%) & $29(15.8 \%)$ & $16(15.0 \%)$ & $13(16.9 \%)$ \\
\hline & $\begin{array}{l}\text { Preconception coun- } \\
\text { selling, } n(\%)\end{array}$ & $122(66.3 \%)$ & $69(64.5 \%)$ & $53(68.8 \%)$ \\
\hline \multirow{8}{*}{$\begin{array}{l}\text { SLE disease } \\
\text { \& therapy } \\
\text { characteristics }\end{array}$} & $\begin{array}{c}\text { Disease duration } \\
\text { (years), median (IQR) }\end{array}$ & $6.7(2.9-10.3)$ & $7.0(3.0-10.0)$ & $6.7(2.1-11.0)$ \\
\hline & Lupus nephritis ${ }^{* 1}$, & $51(27.7 \%)$ & $25(23.4 \%)$ & $26(33.8 \%)$ \\
\hline & $\begin{array}{c}\text { High-risk aPL profile }{ }^{* 2} \\
\mathrm{n}(\%)\end{array}$ & $39(21.3 \%)$ & $21(19.8 \%)$ & $18(23.4 \%)$ \\
\hline & $\begin{array}{c}\text { SLEDAI }{ }^{* 1}, \text { median } \\
(I Q R)\end{array}$ & $2.0(0-4.0)$ & $2.0(0.0-4.0)$ & $2.0(2.0-4.0)$ \\
\hline & Anti-dsDNA, n (\%) & $102(55.7 \%)$ & $47(44.3 \%)$ & 55 (71.4\%) \\
\hline & $\begin{array}{l}\text { Anti-SSA/Ro and/or } \\
\text { Anti-SSB/La, n (\%) }\end{array}$ & $91(49.7 \%)$ & $55(51.9 \%)$ & $36(46.8 \%)$ \\
\hline & Azathioprine ${ }^{* 1}, \mathrm{n}(\%)$ & $38(20.7 \%)$ & $18(16.8 \%)$ & $20(26.0 \%)$ \\
\hline & $\begin{array}{c}\text { Low dose Aspirin }{ }^{3}, \\
n(\%)\end{array}$ & $74(41.1 \%)$ & $34(32.7 \%)$ & $40(52.6 \%)$ \\
\hline \multirow[t]{4}{*}{ Obstetrical history } & Nulliparous, n (\%) & $113(61.4 \%)$ & $63(58.9 \%)$ & $50(64.9 \%)$ \\
\hline & $\begin{array}{c}\text { Previous fetal loss, } \\
\mathrm{n}(\%)\end{array}$ & $39(21.2 \%)$ & $22(20.6 \%)$ & $17(22.1 \%)$ \\
\hline & $\begin{array}{l}\text { Previous (pre-)eclamp- } \\
\text { sia or HELLP, } \mathrm{n}(\%)\end{array}$ & $14(7.6 \%)$ & $8(7.5 \%)$ & $6(7.8 \%)$ \\
\hline & $\begin{array}{l}\text { Previous congenital } \\
\text { heart block, n (\%) }\end{array}$ & $1(0.54 \%)$ & - & $1(1.3 \%)$ \\
\hline \multirow[t]{5}{*}{$\begin{array}{l}\text { Pregnancy } \\
\text { outcome }\end{array}$} & $\begin{array}{c}\text { (mild-moderate) flare }{ }^{*} \text {, } \\
n(\%)\end{array}$ & $44(29.5 \%)$ & $30(34.9 \%)$ & $14(22.2 \%)$ \\
\hline & Preterm birth ${ }^{* 5}, \mathrm{n}(\%)$ & $46(25 \%)$ & $30(28.0 \%)$ & $16(20.8 \%)$ \\
\hline & Preeclampsia, n (\%) & $24(13 \%)$ & $15(14.0 \%)$ & $9(11.7 \%)$ \\
\hline & $\begin{array}{l}\text { Intrauterine growth } \\
\text { restriction, } \mathrm{n}(\%)\end{array}$ & $3(1.7 \%)$ & $1(1.0 \%)$ & $2(2.6 \%)$ \\
\hline & $\begin{array}{l}\text { Congenital heart } \\
\text { block, } \mathrm{n}(\%)\end{array}$ & $1(0.54 \%)$ & - & $1(1.3 \%)$ \\
\hline
\end{tabular}

